\title{
Effects of thermal treatment and nucleating agents on crystallinity, toughness, and stiffness of PLA/PCL blends
}

\author{
Aleksandra Ujcic ${ }^{\circledR}$, Ivan Fortelny, Sabina Krejcikova, Ewa Pavlova, Jiri Hodan, Miroslav Slouf ${ }^{*}$ \\ Institute of Macromolecular Chemistry, Czech Academy of Sciences, 16206 Prague 6, Heyrovskeho nam. 2, \\ Czech Republic
}

Received 29 July 2021; accepted in revised form 13 October 2021

\begin{abstract}
The effects of the thermal treatment and nucleating agents on the morphology, crystallinity, and mechanical properties of poly(lactic acid)/poly(E-caprolactone) (PLA/PCL) blends were studied in order to obtain PLA/PCL blends with both high stiffness and toughness. The standard thermal treatment of the melt-mixed blends (a compression molding without annealing) resulted in the systems with optimized morphology (at PLA/PCL ratio 80/20) and very high toughness (ca 16× higher with respect to neat PLA), but the stiffness at elevated temperatures (above $T_{\mathrm{g}}$ of PLA at $65^{\circ} \mathrm{C}$ ) was low due to the low crystallinity of the PLA matrix $(<10 \%)$. The compression molding with annealing at $110^{\circ} \mathrm{C}$ could increase the crystallinity of PLA (up to $\sim 40 \%$ ), but the toughness decreased steeply due to morphological changes (a coalescence of PCL particles associated with the structure coarsening). The lowering of the annealing temperature (to $80^{\circ} \mathrm{C}$ ) and addition of the PLA nucleating agent ( $1 \mathrm{wt} \%$ of talc) led to the blends showing both high toughness $(9 \times$ with respect to neat PLA) and crystallinity $(\sim 35 \%)$. Dynamic mechanical analysis evidenced that the higher PLA crystallinity improved the storage modulus at temperatures $>60^{\circ} \mathrm{C}$ by $c a$ two orders of magnitude. The achieved combination of the PLA/PCL toughness and stiffness was one of the highest, according to the available literature.
\end{abstract}

Keywords: polymer blends and alloys, poly(lactic acid), poly(E-caprolactone), crystallinity, mechanical properties

\section{Introduction}

Poly(lactic acid) (PLA) is a promising material for a broad range of applications due to its biodegradability, biocompatibility, good processing properties, and high stiffness [1-6]. An important limitation for the applications of neat PLA is its brittleness. The most efficient method that decreases the PLA brittleness is the blending with a minor amount of soft, ductile polymers [7-11]. Recently, we showed that blending of PLA with about $20 \%$ of poly( $\varepsilon$-caprolactone) (PCL) leads to material with a high impact strength, on condition that the preparation, viscosity ratio, and final size of PCL particles are optimized carefully [12-14]. The detailed analysis of the results concerning the PLA/PCL toughness showed that the impact strength of these blends was controlled sensitively not only by the size of PCL particles but also by the crystallinity of the PLA matrix [14].

Commercial grades of PLA are mixtures of L-isomer and a small amount of D-isomer (typically $<10 \mathrm{wt} \%$ ). Therefore, commercial PLA's are semicrystalline. However, the PLA crystallization is rather slow [2, 15-17], frequently slower than the cooling rates used in polymer processing devices [17]. Consequently, the crystallinity of PLA in its blends processed by common procedures is quite low (around $10 \%$ ). Blends with the typical PLA crystallinity $(\sim 10 \%)$ were prepared in our previous studies $[12,13]$. They exhibited very high toughness, but they suffered from softening at temperatures approaching PLA glass transition temperature $\left(T_{\mathrm{g}}\right.$ around $\left.65^{\circ} \mathrm{C}\right)$. This PLA softening does not matter in the great majority ${ }^{*}$ Corresponding author, e-mail: slouf@imc.cas.cz
(C) BME-PT 
of biomedical applications (implants at body temperature around $37^{\circ} \mathrm{C}$ ), but it may cause problems in technical applications (such as packaging, outdoor equipment, or components in the automotive industry), which usually require high stiffness at elevated temperatures.

The classical method how to improve polymer crystallinity is annealing, i.e. keeping the system close to the temperature at which the maximal crystallization rate for given material occurs. However, an unwanted side effect of the annealing of PLA/PCL blends is a possible coalescence of PCL particles. It has been demonstrated that a quite small increase in the PCL particle size decreased the blend toughness drastically [13].

The crystallinity of the PLA matrix can also be enhanced by small amounts of nucleating agents $[15$, 16, 18-21]. Many authors have studied the influence of various substances such as talc, low molecular aliphatic amides or graphene, on the rate of PLA crystallization [15, 18, 19, 21-25]. Li et al. [18] investigated the effect of talc, sodium stearate, and calcium lactate. They found that talc promoted the PLA crystallization effectively in temperatures between 80 and $120^{\circ} \mathrm{C}$. Murariu et al. [16] studied the effect of nanofiller shape (1,2 or 3D) on the PLA matrix crystallization. They found a strong increase in the PLA crystallinity with organo-modified layered silicate, whose surface was treated with ethylene bisstearamide (EBS). Jain et al. [26] prepared PLA/PCL/ talc composites with the majority of PCL and found that talc acted as a nucleating agent for the PCL phase but not for the PLA phase. Bai and coworker [7, 8] used a highly active nucleating agent $\left(N, N^{\prime}, N^{\prime \prime}\right.$-tricyclohexyl-1,3,5-benzene-tricarboxylamide) and increased the crystallinity of PLA matrix up to $50 \%$ for samples prepared by injection molding. Besides the enhancement of crystallinity, they also achieved a high impact strength.

Recent studies on PLA/PCL blends [27-31] showed that the addition of PCL itself influenced the crystallinity of PLA. Rizzuto et al. [27] reported that the addition of PCL accelerated the cold crystallization of PLA, but no significant nucleation effects for PLA/PCL blends were detected when the PLA crystallization started from the molten state. Phroma and Magaraph [28] found a small increase in PLA crystallinity in PLA/PCL blends, but the PLA crystallinity in the blends remained below $10 \%$. Similar results were reported by Khitas et al. [29]: the crystallinity of PLA between 10 and $20 \%$ was found for PLA/PCL blends plasticized with citrates, but the modulus at temperatures above $T_{\mathrm{g}}$ of PLA was not studied. Sundar et al. [30] found an increase in the PLA crystallinity due to an addition of PCL, but a negative effect of PCL on PLA crystallinity was detected by van de Voorde et al. [31]. Thin PLA/PCL films and nanofibers with a low-crystallinity PLA matrix were prepared by Sundar et al. [30] and van de Voorde et al. [31], respectively. All above-listed studies indicated that the enhancement of PLA crystallinity in PLA/PCL blends was a challenging problem, whose solution is needed for efficient utilization of PLA in practice. The nanofillers had usually been added to PLA with the aim to improve mechanical properties of PLA/ PCL blends, but later it was revealed that they could also affect the crystallinity of PLA [32-35]. Oshani et al. [32] added oligomeric silsequioxane (POSS; $0.5 \mathrm{wt} \%$ ) to PLA/PCL/starch blends, which enhanced the PLA crystallinity to $31.6 \%$. However, the storage tensile modulus of the composites steeply decreased with a temperature above $T_{\mathrm{g}}$ of PLA independently of the POSS concentration. Moeinifar et al. [34] found a decrease in the PLA crystallinity in the PLA/PCL blends after POSS addition. Wang et al. [33] found an increase in the crystallinity of PLLA due to an addition of carbon nanotubes but the increase was not evaluated quantitatively. Chomachayi et al. [35] found that silk fibroin nanoparticles enhanced the crystallinity of neat PLA but decreased the crystallization rate of PLA in PLA/PCL blends.

It is worth noting that all above-listed ways of PLA/ PCL blend modification (i.e. the blend annealing, addition of PLA nucleating agents, and addition of nanofillers), which change the crystallinity of PLA matrix, may also influence the PLA/PCL biodegradability. The detailed review of Auras et al. [2] concludes that PLA degrades primarily by hydrolysis in two steps: In the first step, random non-enzymatic chain scission of the ester groups reduces the molecular weight. In the second step, low molecular weight PLA chains can diffuse out of the bulk polymer and be digested by microorganisms to yield carbon dioxide and water. The ester hydrolysis is accelerated by acids or bases. Moreover, any factor which affects the reactivity and/or accessibility of the bulk material with respect to water, such as sample size and shape, temperature, and crystallinity, will influence the polymer degradation rate. The denser structure of PLA samples with increased crystallinity slows down both 
water swelling during the first step and oligomer diffusion to the surface in the second step, which results in certain deceleration of the biodegradation process $[36,37]$.

In this paper, we modified our method of the preparation of a super-tough PLA/PCL blends [12, 13] with the aim to keep the very high blend toughness while enhancing the crystallinity and stiffness of PLA. Talc was used as the nucleating agent, and the thermal treatment of the blends during compression molding was varied. The stiffness of the blends was studied by micromechanical measurements at room temperature and dynamical mechanical analysis in a broad range of temperatures from -90 to $210^{\circ} \mathrm{C}$.

\section{Experimental}

\subsection{Materials}

Two biodegradable polymers, polycaprolactone (PCL; type Capa 6800; Perstorp Group; Sweden; $T_{\mathrm{m}}=60^{\circ} \mathrm{C}$ ) and polylactic acid (PLA; Ingeo 4032D, NatureWorks LLC, USA; $T_{\mathrm{m}}=166^{\circ} \mathrm{C}, M_{\mathrm{n}}=$ $119 \mathrm{kDa}, M_{\mathrm{w}}=207 \mathrm{kDa}, P D I=M_{\mathrm{w}} / M_{\mathrm{n}}=1.74$, content of $\mathrm{D}$-isomer $\approx 1.5 \%$ ), were used in this study. The polymers were selected so that the PLA/PCL viscosity ratio was approximately 1 . Talc (hydrous magnesium silicate in the form of dried powder with average particle size $10 \mu \mathrm{m}$ ) was supplied by SigmaAldrich, USA. Tetrahydrofuran (THF; Lachner, Czech Republic) was used as an etching agent of the PCL phase during the SEM sample preparation.

\subsection{Blend preparation}

Neat PLA and PLA/PCL (80/20) blends with/without $1 \%$ of talc were prepared by a melt-mixing using laboratory batch kneader (Brabender Plasticorder;
Brabender Germany) followed by a compression molding in two hydraulic presses (Fontijne Grotnes, Netherlands). Before the melt-mixing, the polymers were dried in a vacuum oven (PCL: $40^{\circ} \mathrm{C}$ for $12 \mathrm{~h}$; PLA $80^{\circ} \mathrm{C}$ for $4 \mathrm{~h}$ ). A proper amount of talc was put into a small glass bottle which was put for 2 min into an ultrasound bath to destroy big agglomerates. The sonicated talc was immediately dry-mixed with PCL and PLA granulates, and the whole system was meltmixed (mixing chamber: B50 EHT; mixing conditions: $60 \mathrm{rpm}$ for $10 \mathrm{~min}$ at $180^{\circ} \mathrm{C}$ ).

The compression molding conditions were varied in order to get samples with various thermal treatments. The complete list of the ten prepared samples is given in Table 1: six samples were just compression-molded, while four samples were compression molded and annealed.

The compression-molded samples were prepared in three steps: (i) the hot compression molding in the first press $\left(180^{\circ} \mathrm{C}\right.$ for $2 \mathrm{~min}$ at $50 \mathrm{kN}$, followed by 8 min at $220 \mathrm{kN}$ ), (ii) the cold compression molding in the second press $\left(60\right.$ or $80^{\circ} \mathrm{C}$ for $2 \mathrm{~min}$ at $\left.220 \mathrm{kN}\right)$, and (iii) the cooling with water for $15 \mathrm{~min}$ to reach the ambient temperature (cooling rate $\approx 4{ }^{\circ} \mathrm{C} / \mathrm{min}$ ). The samples treated by the compression molding without annealing are denoted with suffix $60 \mathrm{C}$ and 80C (Table 1).

For selected samples (neat PLA and PLA/PCL blends), we combined the compression molding with annealing in order to obtain higher crystallinity of PLA without the addition of talc. In this case, the compression molding of melt-mixed samples consisted of two steps: (i) the hot compression molding in the first press $\left(180^{\circ} \mathrm{C}\right.$ for $2 \mathrm{~min}$ at $50 \mathrm{kN}$, followed by $8 \mathrm{~min}$ at $220 \mathrm{kN}$ ) and (ii) the annealing in the second

Table 1. Summary of prepared PLA/PCL/talc systems.

\begin{tabular}{|l|c|c|c|l|}
\hline \multicolumn{1}{|c|}{ Sample ID } & $\begin{array}{c}\text { PLA } \\
{[\mathbf{w t} \%]}\end{array}$ & $\begin{array}{c}\text { PCL } \\
{[\mathbf{w t} \%]}\end{array}$ & $\begin{array}{c}\text { Talc } \\
{[\mathbf{w t} \%]}\end{array}$ & Basic sample description \\
\hline PLA-60C & 100 & 0 & 0 & PLA compression molded at $60^{\circ} \mathrm{C}$ \\
\hline PLA-An-110C & 100 & 0 & 0 & PLA annealed at $110^{\circ} \mathrm{C}$ \\
\hline PLA/PCL-60C & 80 & 20 & 0 & PLA/PCL blend compression molded at $60^{\circ} \mathrm{C}$ \\
\hline PLA/PCL-80C & 80 & 20 & 0 & PLA/PCL blend compression molded at $80^{\circ} \mathrm{C}$ \\
\hline PLA/PCL-An-80C & 80 & 20 & 0 & PLA/PCL blend annealed at $80^{\circ} \mathrm{C}$ \\
\hline PLA/PCL-An-110C & 80 & 20 & 0 & PLA/PCL blend annealed at $110^{\circ} \mathrm{C}$ \\
\hline PLA/PCL-An-160C & 80 & 20 & 0 & PLA/PCL blend annealed at $160^{\circ} \mathrm{C}$ \\
\hline PLA/PCL/Talc-60C & 79.2 & 19.8 & 1 & PLA/PCL/Talc blend compression molded at $60^{\circ} \mathrm{C}$ \\
\hline PLA/PCL/Talc-80C & 79.2 & 19.8 & 1 & PLA/PCL/Talc blend compression molded at $80^{\circ} \mathrm{C}$ \\
\hline PLA/PCL/Talc-80C-ws & 79.2 & 19.8 & 1 & like previous, but talc without ultrasonication ${ }^{\mathrm{a}}$ \\
\hline
\end{tabular}

For more details about compression molding and annealing, see Section 2.2.

aSample PLA/PCL/Talc-80C-ws: sample without ultrasonic treatment of talc before melt mixing. 
press (the machine preheated to 80 or 110 or $160^{\circ} \mathrm{C}$, the samples pressed at $220 \mathrm{kN}$, and the temperature of hot press decreased down to $50^{\circ} \mathrm{C}$ with cooling rate $\approx 0.4{ }^{\circ} \mathrm{C} / \mathrm{min}$ ). Both compression molding and annealing were always performed with samples closed in a mold so that their shape was preserved. The samples treated by the compression molding and annealing are denoted by suffix An-80C, An-110C, and An-160C (Table 1).

\subsection{Scanning electron microscopy}

The morphology of PLA/PCL/talc composites was visualized by means of scanning electron microscopy (SEM). The micrographs were obtained with a microscope Quanta 200 FEG (FEI; Czech Republic). Before the observation in the electron microscope, all specimens were fixed on metallic support with a conductive silver paste (Leitsilber G302; Christine Groepl, Austria) and sputtered with Pt (vacuum sputter coater SCD 050; Balzers, Germany) in order to minimize charging and sample damage. SEM micrographs were obtained with accelerating voltage $10 \mathrm{kV}$ using secondary electron imaging (SEM/SE). Two different sample preparations were employed: (i) fracture surfaces, prepared under liquid nitrogen in order to minimize plastic deformations, showed the overall morphology of the blends and dispersion of the nucleating agent, while (ii) smoothed surfaces, whose preparation was described in our previous work [38], were etched with THF (THF vapor at $45^{\circ} \mathrm{C}$ for $4 \mathrm{~min}$ ) and employed in determining the particle size distributions by means of program MDISTR [39].

\subsection{Differential scanning calorimetry}

The thermal properties of the samples were studied using a DSC Q2000 instrument (TA Instruments) with nitrogen purge flow $50 \mathrm{~cm}^{3} / \mathrm{min}$. The instrument was calibrated for temperature and heat flow using an indium standard. Samples of about $5 \mathrm{mg}$ were encapsulated into aluminum pans and heated to $200^{\circ} \mathrm{C}$ using the heating rate of $10^{\circ} \mathrm{C} / \mathrm{min}$. Melting points $\left(T_{\mathrm{m}}\right)$ were determined from the position of the melting peak maximum. The crystallinity of PLA matrix $\left(w_{\mathrm{c}, \text { PLA }}\right)$ was calculated according to Equation (1), which considers cold crystallization of the polymer:

$$
w_{\mathrm{c}, \mathrm{PLA}}=\frac{\left|\Delta H_{\mathrm{m}, \mathrm{PLA}}\right|-\left|\Delta H_{\mathrm{cc}, \mathrm{PLA}}\right|}{\Delta H_{\mathrm{m}, \mathrm{PLA}}^{0} \cdot w_{\mathrm{PLA}}} \cdot 100 \%
$$

where $\Delta H_{\mathrm{m}, \mathrm{PLA}}$ is the enthalpy of the PLA melting peak, $\Delta H_{\mathrm{cc}, \mathrm{PLA}}$ is the enthalpy of the PLA cold crystallization peak, $\Delta H_{\mathrm{m}, \mathrm{PLA}}^{0}$ is the melting enthalpy of $100 \%$ crystalline PLA (93.6 J/g; [40]).

\subsection{Impact testing}

Impact testing was carried out with a Charpy impact tester (Ceast Resil Impactor Junior; Ceast S.p.A., Italy). The pendulum work capacity was $4 \mathrm{~J}$ (angle $=$ $150^{\circ}$, speed $3.9 \mathrm{~m} / \mathrm{s}$ ), and the support span was set to $s=62 \mathrm{~mm}$. The experiments were performed at laboratory temperature $\left(22^{\circ} \mathrm{C}\right)$. The testing specimens (ISO 179-1, type 1; at least 6 specimens/sample) were prepared by a compression molding as described in Section 2.2 (dimensions of the specimens: length $L=$ $80 \mathrm{~mm}$, width $W=10 \mathrm{~mm}$, and thickness $B=4 \mathrm{~mm}$ ). The notches (type A), with a depth of $2 \mathrm{~mm}$ and a tip radius of $250 \mu \mathrm{m}$, were prepared with a V-knife. The impact blow was in the edgewise direction of the test specimens. Charpy notched-impact strength $\left(a_{\mathrm{cN}}\right)$ was evaluated according to ISO 179.

\subsection{Dynamic mechanical analysis}

Mechanical properties were tested by a dynamic-mechanical thermal analysis (DMTA). The specimens for the DMTA analysis were cut from compression-molded plates. They were rectangular with the length $=$ $25 \mathrm{~mm}$, width $=10 \mathrm{~mm}$, and thickness $=4 \mathrm{~mm}$. The values of complex modulus $\left|G^{*}\right|$, storage modulus $G^{\prime}$, loss modulus $G^{\prime \prime}$ and damping factor $\tan \delta$ were measured as a function of temperature (ranging from -90 to $210^{\circ} \mathrm{C}$ ) in a rectangular torsion using a Physica MCR 501 rheometer (Anton Paar GmbH). The experiments were performed with temperature ramp $3{ }^{\circ} \mathrm{C} / \mathrm{min}$ and the strain $0.02 \%$, which was in the linear viscoelasticity region (LVE). The LVE was confirmed from strain sweep tests at the frequency of $1 \mathrm{~Hz}$.

\subsection{Microindentation hardness testing}

Micromechanical properties were characterized by instrumented microindentation hardness testing (MHI). The smooth surfaces for the MHI testing were prepared by a microtomy (rotary microtome RM 2155; Leica, Austria) using sharp, freshly broken glass knives (balanced-break glass knife maker EM KMR3; Leica, Austria). The square pyramid diamond indenter (Vickers indenter; the angle between two non-adjacent faces of the square pyramid $=136 \mathrm{deg}$ ) was forced into the specimen surface using a linear loading (loading rate $=25000 \mathrm{mN} / \mathrm{min}$ ) to maximal 
force $200 \mathrm{gf}(1962 \mathrm{mN})$, then kept at the maximal force for $6 \mathrm{~s}$, and released using linear unloading (unloading rate $=25000 \mathrm{mN} / \mathrm{min}$ ). For each sample, we performed at least 30 measurements (at least ten indentations for at least three cut surfaces per sample), and the results were averaged. The indentation hardness $\left(H_{\mathrm{IT}}\right)$, indentation modulus $\left(E_{\mathrm{IT}}\right)$, indentation creep $\left(C_{\mathrm{IT}}\right)$, and elastic part of the indentation work $\left(\eta_{\text {IT }}\right)$ were calculated according to the theory of Oliver and Pharr [41] as described elsewhere [42, 43].

\section{Results and discussion}

In this work, we demonstrate how the annealing and nucleation by talc change the morphology and crystallinity in the PLA/PCL blends (Section 3.1) and how these changes impact the blend toughness (Section 3.2) and stiffness (Section 3.3).

\subsection{Influence of preparation conditions on morphology and crystallinity}

Figure 1 shows the effect of the annealing on the PLA/PCL blend morphology. The average size of the PCL particles (i.e. the average diameter of the PCL particles, $d$, measured from SEM/SE micrographs) in the compression-molded blends (PLA/PCL-60C; Figures $1 \mathrm{a}$ and $1 \mathrm{e} ; d \approx 0.60 \mu \mathrm{m})$ increased just slightly for the blends annealed at a lower temperature of $80^{\circ} \mathrm{C}$ (PLA/PCL-An-80C; Figures $1 \mathrm{~b}$ and 1f;
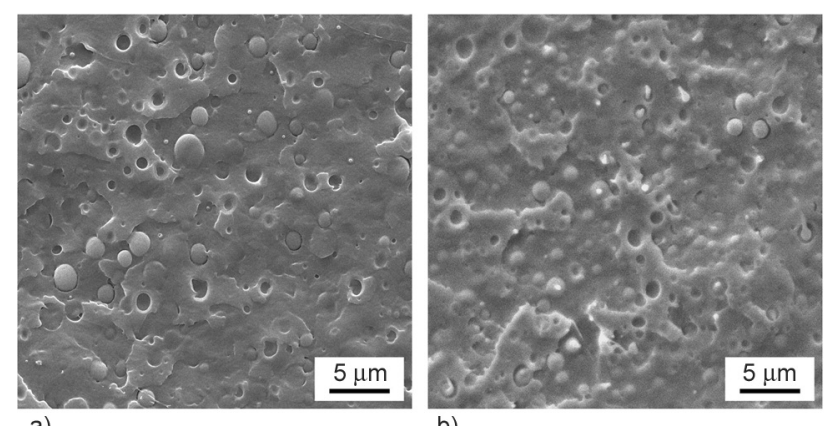

b)

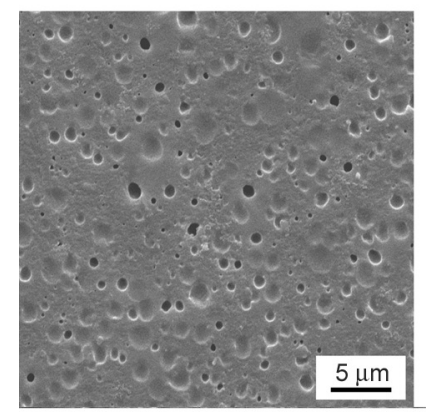

e)

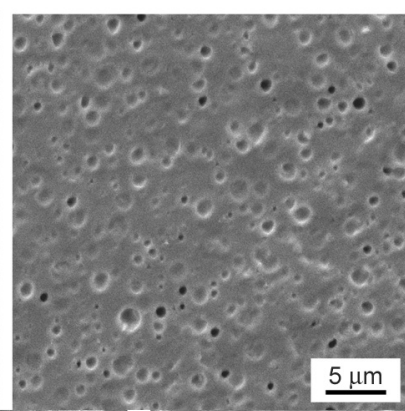

f) $d \approx 0.62 \mu \mathrm{m})$ and then steeply for the blends annealed at higher temperatures (PLA/PCL-An-110C and PLA/PCL-An-160C; Figures 1c, 1d, and 1g, 1h; $d>1 \mu \mathrm{m})$. The effect of the annealing on the PLA matrix crystallinity is summarized in Table 2 : the nonannealed blends (PLA/PCL-60C, PLA/PCL-80C) and the blends annealed at a lower temperature (PLA/PCL-An-80C) exhibited low PLA crystallinity, not differing remarkably from the crystallinity obtained by standard compression molding [12, 13]. On the other hand, the blends annealed at higher temperatures (PLA/PCL-An-110C and PLA/PCLAn-160C) showed substantially higher PLA crystallinity, around $40 \%$.

Figure 2 illustrates the small difference between the average PCL particle size in the neat PLA/PCL blends without talc (Figure 2a) and the PLA/PCL/Talc blends prepared at the same conditions (Figure 2b, $2 c)$. In addition, the comparison of Figures $2 b$ and $2 \mathrm{c}$ evidenced that the ultrasonication improved the dispersion of talc in the polymer matrix significantly. Table 2 demonstrates that the increase in the annealing temperature from 60 to $80^{\circ} \mathrm{C}$ was necessary to enhance the PLA matrix crystallinity of the blends with the addition of talc: The sample annealed at $60^{\circ} \mathrm{C}$ (PLA/PCL/Talc-60C) showed no crystallinity enhancement $\left(w_{\mathrm{c}, \mathrm{PLA}}=10 \%\right.$; a value comparable to neat PLA/PCL blends without annealing), while the

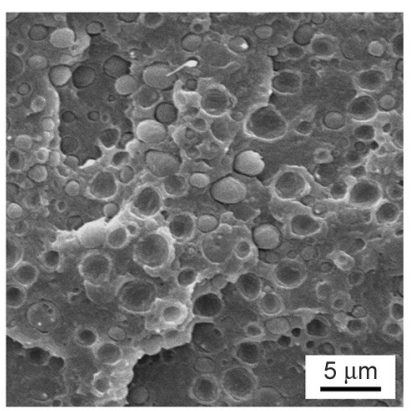

c)

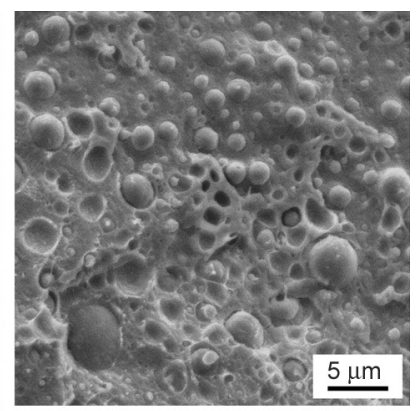

d)

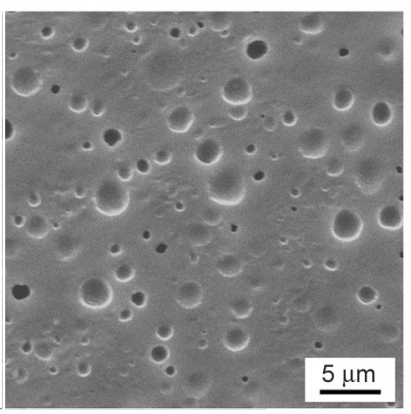

g)

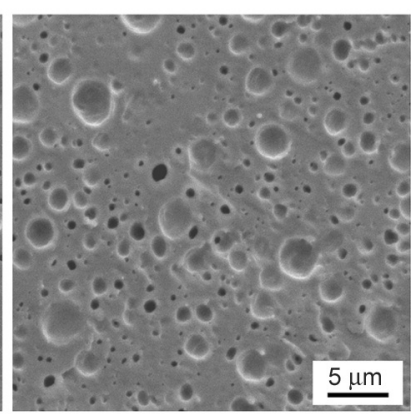

h)

Figure 1. SEM/SE micrographs of (a-d) cryo-fractured surfaces and $(\mathrm{e}-\mathrm{h})$ smoothed and etched surfaces of PLA/PCL blends with various thermal treatments: (a, e) PLA/PCL-60C, (b, f) PLA/PCL-An-80C, (c, g) PLA/PCL-An-110C, and (d, h) PLA/PCL-An-160C. 
Table 2. DSC results.

\begin{tabular}{|c|c|c|c|c|c|}
\hline Sample ID & $\begin{array}{c}T_{\text {cc,PLA }} \\
{\left[{ }^{\circ} \mathbf{C}\right]}\end{array}$ & $\begin{array}{c}\Delta H_{\text {cc,PLA }} \\
{[\mathrm{J} / \mathrm{g}]}\end{array}$ & $\begin{array}{c}T_{\mathrm{m}, \mathrm{PLA}} \\
{\left[{ }^{\circ} \mathrm{C}\right]}\end{array}$ & $\begin{array}{c}\Delta H_{\mathrm{m}, \mathrm{PLA}} \\
{[\mathrm{J} / \mathrm{g}]}\end{array}$ & $\begin{array}{c}w_{\mathrm{c}, \mathrm{PLA}} \\
{[\mathrm{wt} \%]}\end{array}$ \\
\hline PLA-60C & 110.8 & -27.3 & 169.0 & 34.1 & 7.3 \\
\hline PLA-An-110C & - & - & 170.8 & 36.5 & 39.2 \\
\hline PLA/PCL-60C & 95.0 & -19.3 & 166.8 & 25.7 & 8.6 \\
\hline PLA/PCL-80C & 92.2 & -20.4 & 168.6 & 28.0 & 10.2 \\
\hline PLA/PCL-An-80C & 93.2 & -20.5 & 167.1 & 26.9 & 8.6 \\
\hline PLA/PCL-An-110C & - & - & 167.0 & 29.4 & 39.5 \\
\hline PLA/PCL-An-160C & - & - & 163.8 & 31.5 & 42.3 \\
\hline PLA/PCL/Talc-60C & 93.7 & -19.8 & 166.8 & 27.0 & 9.7 \\
\hline PLA/PCL/Talc-80C & - & - & 168.7 & 26.3 & 35.7 \\
\hline PLA/PCL/Talc-80C-ws & - & - & 168.4 & 28.9 & 39.2 \\
\hline
\end{tabular}

$T_{\text {cc,PLA }}{ }^{-}$temperature of PLA cold crystallization

$\Delta H_{\mathrm{cc}, \mathrm{PLA}}-$ enthalpy of PLA cold crystallization

$T_{\mathrm{m}, \mathrm{PLA}}-\quad$ PLA melting temperature

$\Delta H_{\mathrm{m}, \mathrm{PLA}}-$ PLA melting enthalpy

$w_{\mathrm{c}, \mathrm{PLA}}-\quad$ degree of PLA crystallinity

More detailed description of samples is given in Table 1.

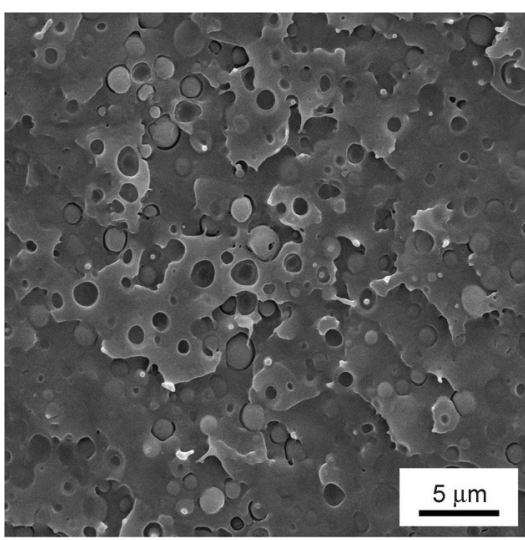

a)

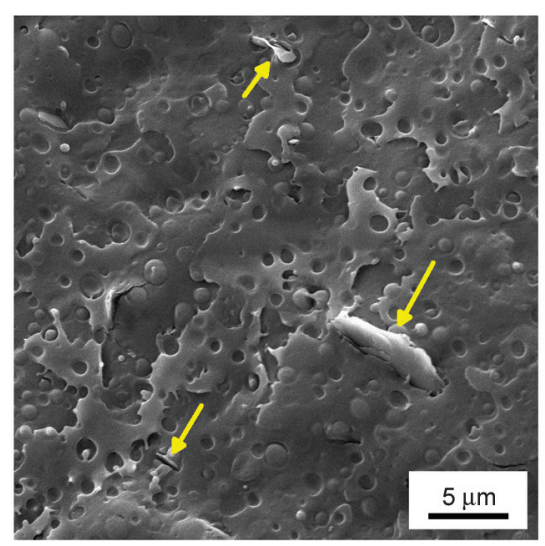

b)

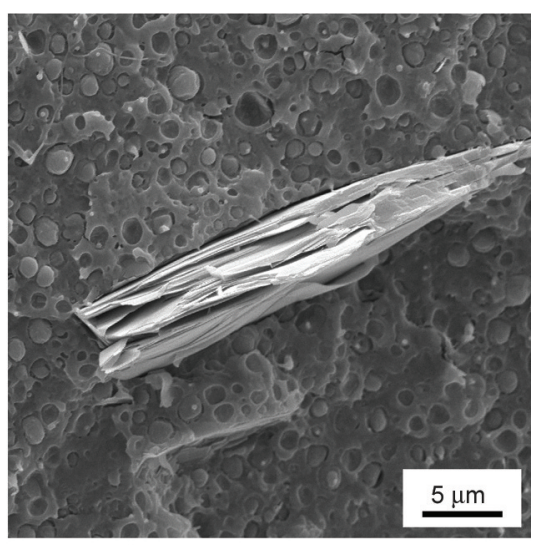

c)

Figure 2. SEM/SE micrographs of cryo-fractured surfaces of (a) PLA/PCL-60C, (b) PLA/PCL/talc-80C, and (c) PLA/ PCL/talc-80C-ws systems. The micrographs illustrate small impact of filler on PCL particle size (Figure 2a vs. Figures $2 \mathrm{~b}-2 \mathrm{c}$ ), and poor dispersion of talc without sonication (Figure $2 \mathrm{~b} v \mathrm{~s}$. Figure $2 \mathrm{c}$ ). The arrows in Figure $2 \mathrm{~b}$ denote talc particles.

sample annealed at $80^{\circ} \mathrm{C}$ (PLA/PCL/Talc-80C) achieved much higher PLA-crystallinity $\left(w_{\mathrm{c}, \mathrm{PLA}}=\right.$ $36 \%$; a value comparable to neat PLA/PCL blends annealed at 110 or $160^{\circ} \mathrm{C}$ ). Evidently, the annealing temperature had to be increased sufficiently above the glass transition temperature of PLA $\left(T_{\mathrm{g}} \approx 55-\right.$ $\left.65^{\circ} \mathrm{C} ;[4,13]\right)$ in order to start additional crystallization of PLA, leading to the desired crystallinity increase. This behavior of PLA has already been reported [2].

\subsection{Influence of morphology and crystallinity on toughness}

Figure 3 compares the degree of crystallinity, $w_{\mathrm{cPLA}}$, and Charpy notched impact strength, $a_{\mathrm{N}}$, of all prepared samples. The blends without talc exhibiting a low crystallinity (PLA/PCL-60C, PLA/PCl-80C, and PLA/PCL-An-80C) achieved a high impact strength. The annealing at $80^{\circ} \mathrm{C}$ (PLA/PCL-An-80C) led to an even slightly higher impact strength than in our preceding studies $[12,13]$. However, the annealing at higher temperatures (PLA/PCL-An-110C and PLA/ PCL-An-160C blends) resulted in the expected increase in the PLA matrix crystallinity, but it also decreased the impact strength drastically. The observed decrease in the impact strength could be attributed to the coalescence of PCL particles, whose average size was much higher than in the blends prepared by a standard compression molding (Figure 1). From the point of view of toughness, the optimal PCL particle size was lower for PLA/PCL blends with a highcrystallinity PLA matrix than for the blends with a 


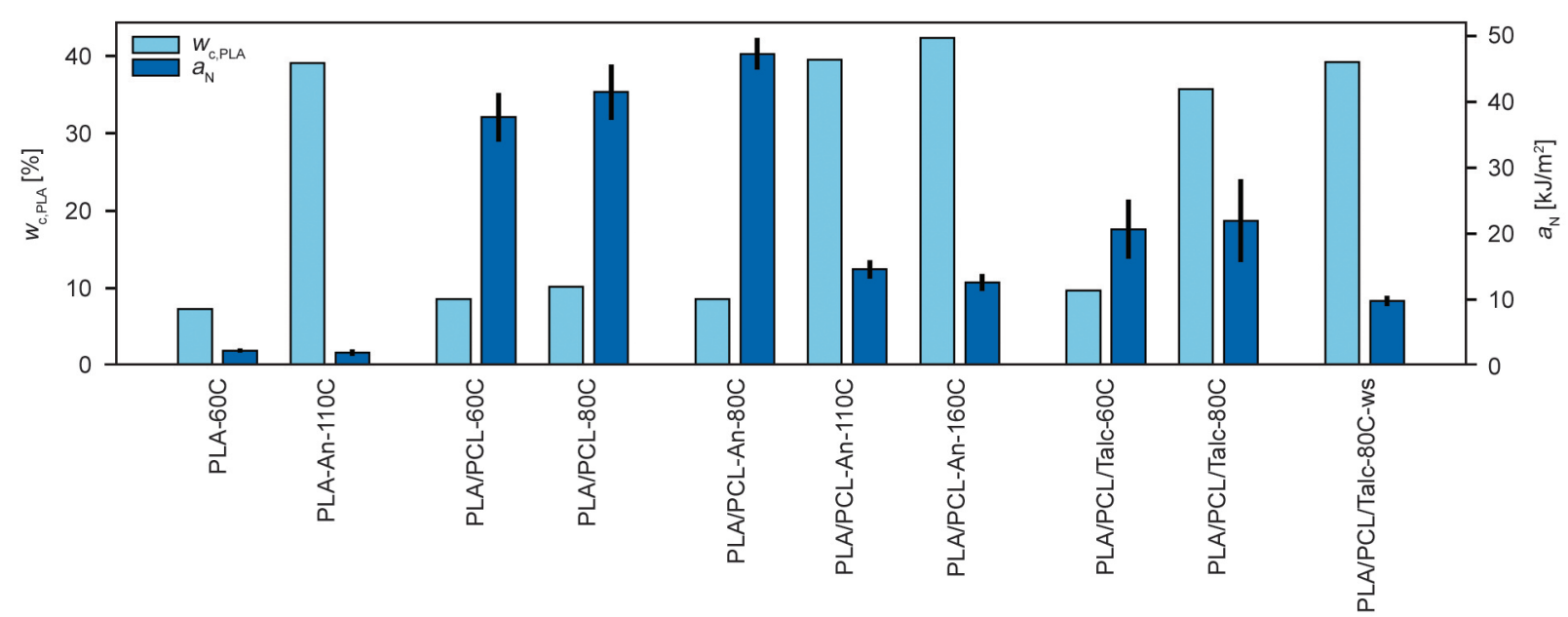

Figure 3. Crystallinity ( $\left.w_{\mathrm{c}, \text { PLA }}\right)$ and Charpy notched impact strength $\left(a_{\mathrm{N}}\right)$ of PLA/PCL systems. The graph illustrates complex influence of processing conditions on two key parameters of the systems. The sample names and compositions are explained in Table 1.

low-crystallinity PLA matrix [7, 8]. This effect was explained and also exemplified in our recent review [14]. Therefore, the simultaneous increase in both PCL particle size and PLA matrix crystallinity ruined the impact strength of the blends completely.

The addition of $1 \mathrm{wt} \%$ of talc (samples PLA/PCL/ Talc-60C and PLA/PCL/Talc-80C) led to a circa $50 \%$ decrease in the impact strength with respect to the neat blends with the low-crystallinity PLA matrix (samples PLA/PCL-60C, PLA/PCL-80C and PLA/PCL-An-80C). On the other hand, the PLA/ PCL/Talc- $80 \mathrm{C}$ with crystallinity $36 \%$ exhibited a substantially higher impact strength than PLA/PCL-An110C, and PLA/PCL-An-160C blends with the comparable crystallinity. It is worth noting that the impact strength of PLA/PCL/Talc-80C was still about ten times higher than that of neat PLA. Therefore, PLA/ PCL/Talc-80C sample showed the best balance between the crystallinity enhancement and high impact strength. As the crystallinity increase in the PLA/ PCL/Talc-80C system was sufficient, it was redundant to test talc-nucleated PLA/PCL blends prepared at even higher temperatures. The elevated temperatures could increase the PLA crystallinity just by a few percent (as evidenced by Table 2) which would not influence the PLA/PCL stiffness significantly (as confirmed in Figure 5). Moreover, the elevated processing temperatures promoted PCL particle coalescence (as illustrated in Figure 1), which led to a significant decrease in the PLA/PCL toughness (as documented in Figure 3 and explained in a recent review of Fortelny et al. [14]).

The fine and homogeneous distribution of talc in the PLA/PCL blends was necessary to achieve the high toughness of PLA/PCL/Talc samples. The blends prepared with ultrasonicated talc (PLA/PCL/Talc-80C) exhibited the finer distribution of talc in the polymer matrix (Figure 2b) and high impact strength (Figure 3, $a_{\mathrm{N}} \sim 20 \mathrm{~kJ} / \mathrm{m}^{2}$ ), while the blends prepared with nonsonicated talc (PLA/PCL/Talc-80C-ws) contained the large talc agglomerates (Figure 2c) and lower impact strength (Figure 3, $a_{\mathrm{N}} \sim 10 \mathrm{~kJ} / \mathrm{m}^{2}$ ). The detailed analysis of SEM micrographs (not shown for the sake of brevity) indicated that the distribution of talc in PLA/PCL blends somewhat differed from place to place even within the samples prepared by the same procedure. This led to the higher standard deviations of $a_{\mathrm{N}}$ values of PLA/PCL/Talc with respect to that of PLA/PCL samples. Our interpretation that the large talc agglomerates had a detrimental effect on the impact strength of blends was in agreement with the results obtained for the analogous blends containing talc with and without sonication (PLA/PCL/Talc-80C and PLA/PCL/Talc-80C-ws): the impact strength of PLA/PCL/Talc-80C-ws was only about the half of the impact strength of PLA/PCL/Talc-80C in spite of similar PLA matrix crystallinities of both samples. Furthermore, these results suggested that even better toughness might have been achieved by further improvement of the preparation procedure, leading to even finer dispersion of talc in the PLA/PCL matrix. Figure 4 compares the fracture surfaces of the samples from an impact test (samples PLA/PCL-80C and PLA/PCL/Talc-80C with the higher and lower impact strengths, respectively). The fracture surface of PLA/PCL-80C sample with the high impact strength (Figure 4a) was smoother, and the PCL particles were hardly recognizable, which could be attributed to the 


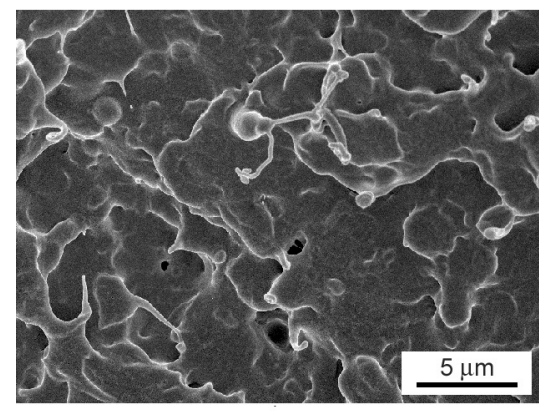

a)

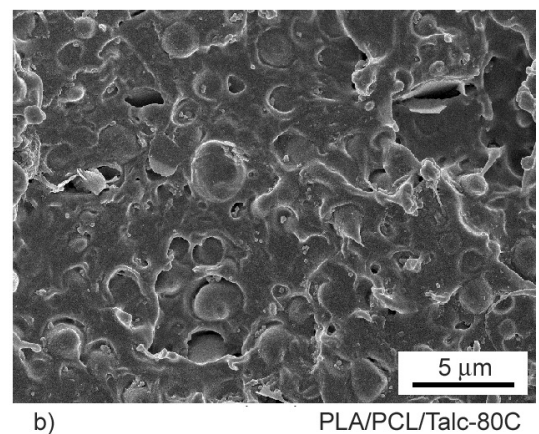

b)
PLA/PCL/Talc-80C

Figure 4. SEM micrographs comparing fracture surfaces from notched Charpy impact tests: (a) PLA/PCL-80C blend with very high toughness and (b) PLA/PCL/Talc-80C blend with medium toughness. PCL particles were visible more clearly on the fracture surfaces of the blends with lower toughness (b), which indicated that the fracture tended to propagate along the PLA/PCL interface and, consequently, the energy dissipation was lower in the lower-toughness systems.

plastic deformations of the PCL particles during fracture. These plastic deformations of the PCL particles could have contributed to the total fracture energy dissipation. The fracture surface of PLA/PCL/Talc80C sample with lower impact strength (Figure 4b) exhibited a higher density of fracture lines and contained easily detectable PCL particles with lower plastic deformations. This suggested that the fracture was more brittle, propagated more on the matrix/particle interphase, and the total fracture energy was not as much dissipated due to the deformation of particles as in the case of sample PLA/PCL/80C. A similar behavior, i.e. the lower plastic deformations of minority phase particles during fracture of PLA/PCL systems with the lower toughness, was observed in our previous study [13].

The above-described results demonstrated that the PLA/PCL blends with the high impact strength and enhanced crystallinity could hardly be prepared without the addition of nucleating agents. The time for which the blends had to be kept at an elevated temperature (in order to increase PLA matrix crystallinity) was too long, which resulted in a substantial increase in the PCL particle size (due to the particle coalescence at elevated temperature), and this was detrimental for the toughness of the PLA/PCL blends. The addition of talc as a nucleating agent enabled us to obtain PLA/PCL blends with the enhanced crystallinity when the original conditions of the compression molding were just slightly modified, i.e. the temperature in the cold press was increased from 60 to $80^{\circ} \mathrm{C}$. Careful control of the quality of the talc dispersion was found necessary in order to achieve a sufficient toughness of PLA/PCL/ Talc samples.

\subsection{Influence of crystallinity on stiffness}

The stiffness of selected PLA/PCL systems was characterized by instrumented microindentation hardness testing (MHI) and dynamic mechanical thermal analysis (DMTA). The MHI measurements were performed at the laboratory temperature, at which the PLA crystallinity played a minor role, as justified below. The DMTA measurements covered a broader temperature range (from -90 to $200^{\circ} \mathrm{C}$ ), being focused on the behavior of the materials above the laboratory temperature, where we anticipated a much stronger influence of the PLA crystallinity on the mechanical performance.

In the MHI testing (Figure 5a), the stiffness was characterized by means of indentation modulus $\left(E_{\mathrm{IT}}\right)$ and indentation hardness $\left(H_{\mathrm{IT}}\right)$. The values of $E_{\mathrm{IT}}$ are approximately equal to macroscopic tensile modulus $(E)$ and other relevant macroscopic moduli $\left(E_{\mathrm{IT}} \approx E\right.$; $[41,44])$, while the values of HIT are proportional to macroscopic yield strength $(Y)$ according to Tabor's relation $\left(H_{\mathrm{IT}} \approx 3 Y\right.$; [45]). Both properties showed the same main trends: (i) a strong increase in the stiffness with the PLA amount and (ii) a moderate increase in the stiffness with the PLA crystallinity. The strong correlation between $E_{\mathrm{IT}}$ and $H_{\mathrm{IT}}$ (Figure 5b) was in agreement with theoretical predictions of Struik [46], who had shown that the yield strength of amorphous and semicrystalline polymers is proportional to their elastic modulus $(E \approx 30 Y)$. The combination of Struik's relation and Tabor's relation gives an approximate formula (Equation (2)) that holds for amorphous and semicrystalline polymers:

$E \approx E_{\mathrm{IT}} \approx 30 Y \approx 10 H_{\mathrm{IT}}$ 

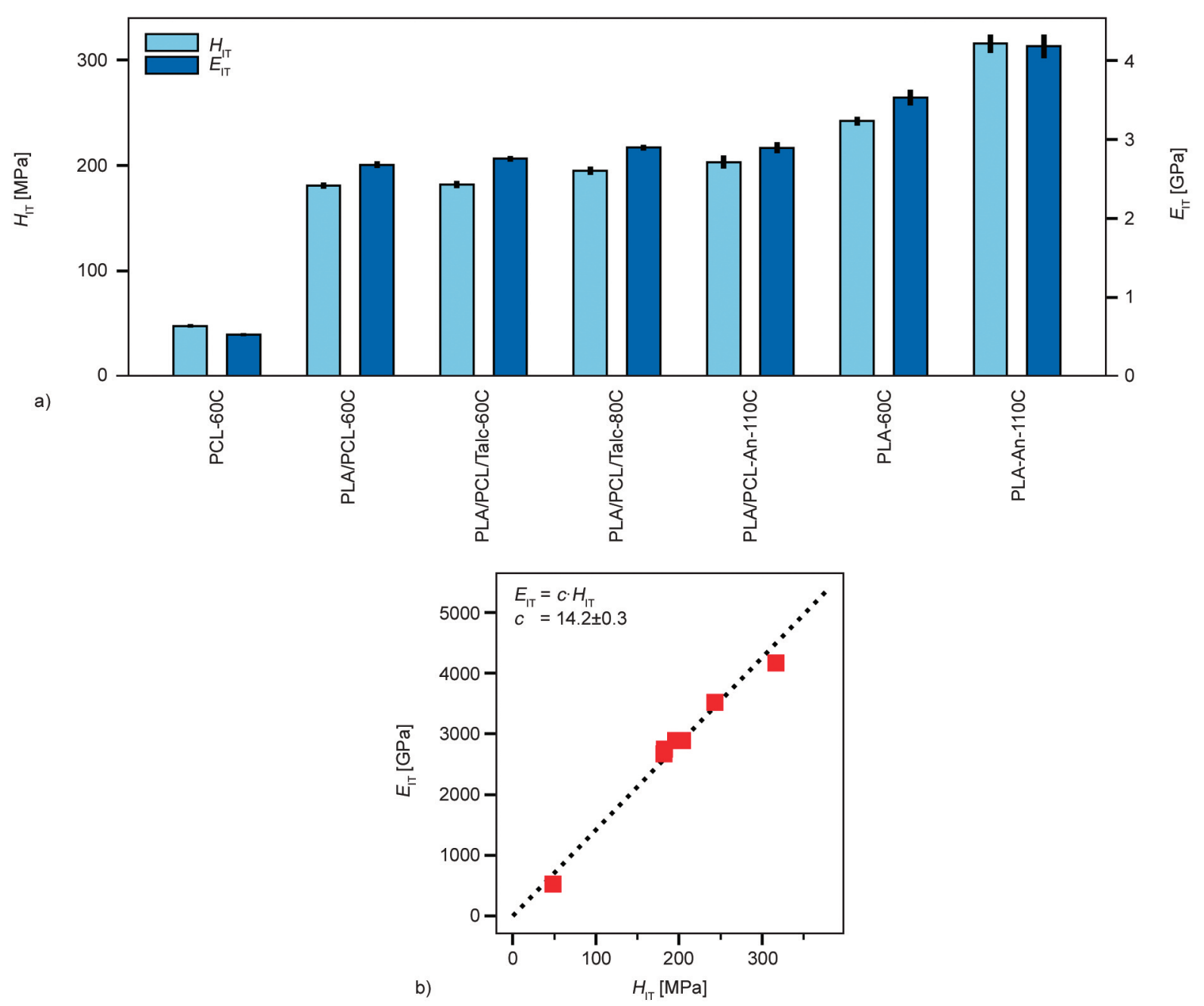

Figure 5. Microindentation hardness testing results for selected PLA/PCL systems: (a) values of indentation hardness $\left(H_{\mathrm{IT}}\right)$ and indentation modulus $\left(E_{\mathrm{IT}}\right)$ with error bars representing standard deviations and (b) verification of theoretically predicted linear correlation between $H_{\mathrm{IT}}$ and $E_{\mathrm{IT}}$.

where $E$ represents a macroscale elastic modulus, $E_{\mathrm{IT}}$ is a microindentation modulus, $Y$ is a macroscale yield strength, and $H_{\mathrm{IT}}$ is a microindentation hardness. Although Equation (2) is based on many simplifications, the linear relationship between the four quantities $\left(E, E_{\mathrm{IT}}, Y, H_{\mathrm{IT}}\right)$ holds surprisingly well for many polymer systems consisting of both amorphous and semicrystalline polymers, as evidenced in numerous previous studies [12, 38, 46-50]. In our case, the linearity between $E_{\mathrm{IT}}$ and $\mathrm{H}_{\mathrm{IT}}$ was evident (Figure $5 \mathrm{~b}$ ), and the proportionality constant $(c=14.2)$ was in a reasonable agreement with the theoretical prediction (Equation (2): $E_{\mathrm{IT}} \approx 10 H_{\mathrm{IT}} \rightarrow c \approx 10$ ), which confirmed the reliability, reproducibility, and correctness of our micromechanical measurements. The strong increase in both $E_{\mathrm{IT}}$ and $H_{\mathrm{IT}}$ with the increasing amount of PLA corresponded to general trends, theories, and/or predictive models for polymer blends, such as EBM [13, 45, 51]. The moderate increase in
HIT with PLA crystallinity could be justified by means of the relation found by Balta-Calleja and Kilian [52], which holds for the microhardness of semicrystalline polymers (Equation (3)):

$H=v_{\mathrm{a}} H_{\mathrm{a}}+v_{\mathrm{c}} \frac{H_{\mathrm{c}}^{0}}{1+\frac{b}{l_{\mathrm{c}}}}$

where $H$ is a microhardness, $v_{\mathrm{a}}$ and $v_{\mathrm{c}}$ is a volume fraction of amorphous and crystalline phase, respectively, $l_{\mathrm{c}}$ is an average thickness of crystalline lamellae, and $H_{\mathrm{c}}^{\infty}$ is a constant (for given experimental conditions) that corresponds to the hardness of the infinitely thick crystalline lamellae, and $b$ is another constant (for given experimental conditions) related to surface and deformation energy of the lamellae [47]. In the case of our systems at ambient temperature, PLA exhibited high stiffness even at low crystallinities due to its high glass transition temperature $\left(T_{\mathrm{g}} \approx\right.$ $65^{\circ} \mathrm{C}$ ), which resulted in the high microhardness of 
the amorphous phase $\left(H_{\mathrm{a}}\right)$ as justified elsewhere [13, 47]. Thus the increase in the PLA crystallinity influenced the final stiffness of PLA/PCL blends at laboratory temperature quite moderately (compare $w_{\mathrm{c}, \mathrm{PLA}}, H_{\mathrm{IT}}$, and $E_{\mathrm{IT}}$ in Figures 3 and 4 ). However, at the elevated temperatures closer to the $T_{\mathrm{g}}$ of PLA (i.e. at the temperatures where the contribution of $v_{\mathrm{a}} H_{\mathrm{a}}$ member in the right-hand side of Equation (3) was minimized due to a steep decrease of $H_{\mathrm{a}}$ ), the crystallinity started to play a more important role, as discussed in the following paragraphs.

The DMTA experiments (Figure 6) completed the results obtained from the DSC and MHI measurements. The samples with the higher PLA crystallinity exhibited a higher stiffness (storage moduli, $G^{\prime}$ ) in the whole temperature range (Figure 6a). As expected, the moduli of the blends somewhat decreased with the addition of PCL (in comparison with neat PLA). The glass transition of the PCL phase was slightly shifted to the lower temperatures: from $-57^{\circ} \mathrm{C}$ for pure PCL to $-63^{\circ} \mathrm{C}$ in the case of PLA/PCL and PLA/PCL/Talc systems (Figure 6b). This could be explained by the enhanced motion of PCL molecular segments in the amorphous phase after the addition of PLA due to the reduced amount of entanglements at the PLA-PCL interface [53]. The glass transition of PLA slightly increased with the increasing crystallinity. The higher number of crystalline regions restricted molecular movements also in the amorphous phase, which caused an increase in $T_{\mathrm{g}}$ [54]. Logically, the higher peaks related to $T_{\mathrm{g}}$ of PLA were observed for samples with the lower crystallinity (due to the higher content of the amorphous phase).

The dependence of $G^{\prime}$ on temperature provided information about the stiffness of PLA/PCL blends with various crystallinities of PLA matrix. Figure $6 \mathrm{a}$ documented that the modulus of the blends with the low-crystallinity PLA matrix $(<10 \%)$ dropped from $\sim 500$ to $\sim 1 \mathrm{MPa}$ for temperatures above $T_{\mathrm{g}}$ of PLA $\left(>65^{\circ} \mathrm{C}\right)$. The increase in $G^{\prime}$ at even higher temperatures was caused apparently by the PLA cold crystallization during the DMTA measurements. A similar dependence of the modulus of PLA/PCL blends on temperature was found by Bai et al. [8]. In contrast, the decrease in $G^{\prime}$ above $T_{\mathrm{g}}$ of PLA for the blends with the PLA crystallinity above $35 \%$ was much lower. These blends with a high-crystallinity matrix exhibited $G^{\prime}$ about $20 \mathrm{MPa}$ even at temperatures close to the melting temperature of PLA. These results demonstrated clearly that the PLA/PCL blends with the PLA matrix crystallinity of around $35 \%$ could serve in many applications at temperatures above $T_{\mathrm{g}}$ of PLA, where the PLA/PCL blends with a low-crystallinity matrix would fail due to their negligible stiffness.

\section{Conclusions}

In our previous work $[12,13]$, we developed $»$ supertough « PLA/PCL(80/20) blends, whose stiffness at ambient temperature was very good and toughness was $c a 16 \times$ higher in comparison with the neat PLA matrix. The crystallinity of the PLA matrix in the blends was $\sim 10 \%$. Therefore, the blends could be employed in medical applications (temperatures $<40^{\circ} \mathrm{C}$ ), but not for all material and/or outdoor applications (temperatures exceeding $50-60^{\circ} \mathrm{C}$ ). This was due to the low crystallinity of the PLA matrix, which lost its stiffness drastically at temperatures approaching $T_{\mathrm{g}}$ of PLA $\left(65^{\circ} \mathrm{C}\right)$. The objective of this work was to obtain the PLA/PCL blends with both high toughness at ambient temperature and higher stiffness at elevated temperatures. The main results can be summarized as follows:

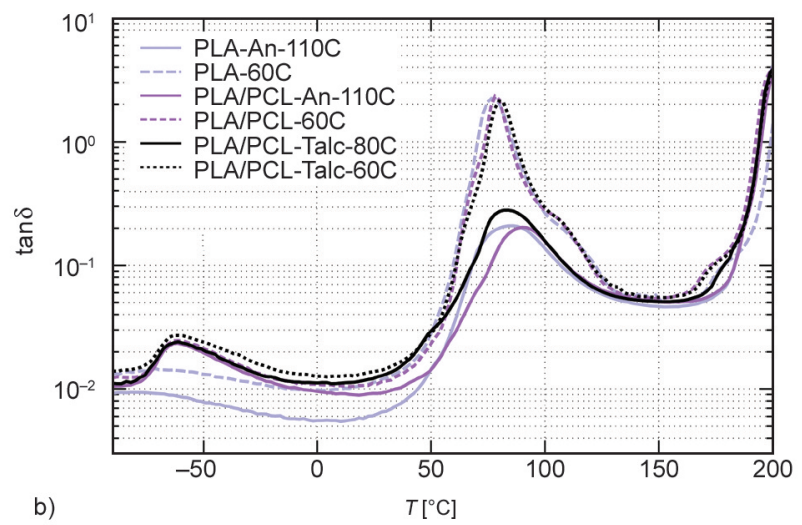

a)

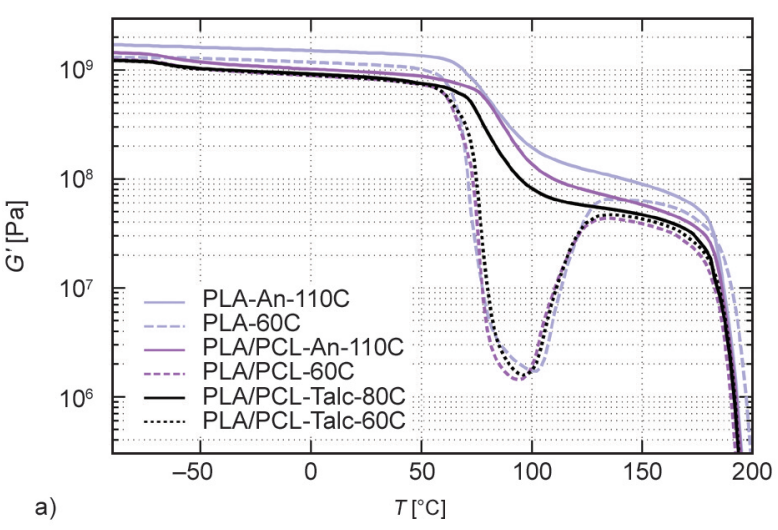

b)

(a) Storage modulus $G^{\prime}$ and (b) damping factor $\tan \delta$ as a function of temperature. 
1. Standard thermal treatment of PLA/PCL blends with optimized composition and processing (as described in our previous studies) repeatedly resulted in a material with a high toughness (which confirmed reproducibility of our optimized preparation procedure), but the blends suffered from a low stiffness at elevated temperatures due to the low crystallinity of the PLA matrix, not exceeding $10 \%$.

2. Annealing of the PLA/PCL blends increased the crystallinity of the PLA matrix and the overall blend stiffness at elevated temperatures but compromised the final toughness due to morphological changes: the coalescence of PCL particles during annealing decreased the toughness strongly.

3. The best results were obtained by the optimization of the annealing temperature (optimal value of $\left.80^{\circ} \mathrm{C}\right)$, cooling rate $\left(0.4{ }^{\circ} \mathrm{C} / \mathrm{min}\right)$, and by the addition of a suitable nucleating agent $(1 \mathrm{wt} \%$ of talc). The final PLA/PCL blends exhibited both high toughness $(9 \times$ higher with respect to neat PLA) and high crystallinity ( $\sim 35 \%)$, which resulted in a higher stiffness at elevated temperatures.

4. A dynamic mechanical thermal analysis demonstrated the substantially enhanced stiffness of PLA/PCL/talc systems with the high-crystallinity matrix in the range between the glass transition and melting temperature of PLA. The storage modulus in this region increased up to two orders of magnitude. Therefore, the high-crystallinity matrix PLA/PCL blends could be employed in a broader range of applications, in which not only a good stiffness but also a sufficient toughness at elevated temperatures is required. According to the available literature, the achieved combination of the impact strength and crystallinity of the PLA/PCL blends was one of the highest. Moreover, the preparation procedure is quite simple and flexible, which means that it can be further optimized for even better mechanical performance.

\section{Acknowledgements}

Financial support through grant NU21-06-00084 (Czech Health Research Council) is gratefully acknowledged.

\section{References}

[1] Middleton J. C., Tipton A. J.: Synthetic biodegradable polymers as orthopedic devices. Biomaterials, 21, 2335-2346 (2000).

https://doi.org/10.1016/S0142-9612(00)00101-0

[2] Auras R., Harte B., Selke S.: An overview of polylactides as packaging materials. Macromolecular Bioscience, 4, 835-864 (2004).

https://doi.org/10.1002/mabi.200400043

[3] Boccaccini A. R., Blaker J. J., Maquet V., Chung W., Jérôme R., Nazhat S. N.: Poly(D,L-lactide) (PDLLA) foams with $\mathrm{TiO}_{2}$ nanoparticles and PDLLA/TiO 2 -Bioglass ${ }^{\circledR}$ foam composites for tissue engineering scaffolds. Journal of Materials Science, 41, 3999-4008 (2006).

https://doi.org/10.1007/s10853-006-7575-7

[4] Lim L-T., Auras R., Rubino M.: Processing technologies for poly(lactic acid). Progress in Polymer Science, 33, 820-852 (2008).

https://doi.org/10.1016/j.progpolymsci.2008.05.004

[5] Hamad K., Kaseem M., Yang H. W., Deri F., Ko Y. G.: Properties and medical applications of polylactic acid: A review. Express Polymer Letters, 9, 435-455 (2015). https://doi.org/10.3144/expresspolymlett.2015.42

[6] Murariu M., Dubois P.: PLA composites: From production to properties. Advanced Drug Delivery Reviews, 107, 17-46 (2016).

https://doi.org/10.1016/j.addr.2016.04.003

[7] Bai H., Xiu H., Gao J., Deng H., Zhang Q., Yang M., $\mathrm{Fu}$ Q.: Tailoring impact toughness of poly(L-lactide)/ poly( $\varepsilon$-caprolactone) (PLLA/PCL) blends by controlling crystallization of PLLA matrix. ACS Applied Materials and Interfaces, 4, 897-905 (2012).

https://doi.org/10.1021/am201564f

[8] Bai H., Huang C., Xiu H., Gao Y., Zhang Q., Fu Q.: Toughening of poly(L-lactide) with poly( $\varepsilon$-caprolactone): Combined effects of matrix crystallization and impact modifier particle size. Polymer, 54, 5257-5266 (2013).

https://doi.org/10.1016/j.polymer.2013.07.051

[9] Imre B., Pukánszky B.: Compatibilization in bio-based and biodegradable polymer blends. European Polymer Journal, 49, 1215-1233 (2013).

https://doi.org/10.1016/j.eurpolymj.2013.01.019

[10] Urquijo J., Guerrica-Echevarría G., Equiazábal J. I.: Melt processed PLA/PCL blends: Effect of processing method on phase structure, morphology, and mechanical properties. Journal of Applied Polymer Science, 132, 42641 (2015). https://doi.org/10.1002/app.42641

[11] Zhao X., Hu H., Wang X., Yu X., Zhou W., Peng S.: Super tough poly(lactic acid) blends: A comprehensive review. RSC Advances, 10, 13316-13368 (2020). https://doi.org/10.1039/D0RA01801E 
[12] Ostafinska A., Fortelny I., Nevoralova M., Hodan J., Kredatusova J., Slouf M.: Synergistic effects in mechanical properties of PLA/PCL blends with optimized composition, processing, and morphology. RSC Advances, 5, 98971-98982 (2015). https://doi.org/10.1039/C5RA21178F

[13] Ostafinska A., Fortelný I., Hodan J., Krejčíková S, Nevoralová M., Kredatusová J., Kruliš Z., Kotek J., Šlouf M.: Strong synergistic effects in PLA/PCL blends: Impact of PLA matrix viscosity. Journal of the Mechanical Behavior of Biomedical Materials, 69, 229-241 (2017). https://doi.org/10.1016/j.jmbbm.2017.01.015

[14] Fortelny I., Ujcic A., Fambri L., Slouf M.: Phase structure, compatibility, and toughness of PLA/PCL blends: A review. Frontiers in Materials, 6, 206 (2019). https://doi.org/10.3389/fmats.2019.00206

[15] Liu G., Zhang X., Wang D.: Tailoring crystallization: Towards high-performance poly(lactic acid). Advanced Materials, 26, 6905-6911 (2014). https://doi.org/10.1002/adma.201305413

[16] Murariu M., Dechief A-L., Ramy-Ratiarison R., Paint Y., Raquez J-M., Dubois P.: Recent advances in production of poly(lactic acid) (PLA) nanocomposites: A versatile method to tune crystallization properties of PLA. Nanocomposites, 1, 71-82 (2015). https://doi.org/10.1179/2055033214Y.0000000008

[17] Zhang M., Shi X., Dia X., Huo C., Xie J., Li X., Wang $\mathrm{X}$.: Improving the crystallization and fire resistance of poly(lactic acid) with nano-ZIF-8@GO. Journal of Materials Science, 53, 7083-7093 (2018). https://doi.org/10.1007/s10853-018-2049-2

[18] Li H., Huneault M. A.: Effect of nucleation and plasticization on the crystallization of poly(lactic acid). Polymer, 48, 6855-6866 (2007). https://doi.org/10.1016/j.polymer.2007.09.020

[19] Harris A. M., Lee E. C.: Improving mechanical performance of injection molded PLA by controlling crystallinity. Journal of Applied Polymer Science, 107, 22462255 (2008).

https://doi.org/10.1002/app.27261

[20] Cipriano T. F., da Silva A. L. N., da Fonseca Thomé da Silva A. H. M., de Sousa A. M. F., da Silva G. M., do Nanscimento C. R.: Rheological and morphological properties of composites based on polylactide and talc. Journal of Materials Science and Engineering B, 3, 695-699 (2013).

https://doi.org/10.17265/2161-6221/2013.11.002

[21] Liu X., Wang T., Chow L. C., Yang M., Mitchell J. W.: Effect of inorganic fillers on the thermal and mechanical properties of poly(lactic acid). International Journal of Polymer Science, 2014, 827028 (2014). https://doi.org/10.1155/2014/827028

[22] Xing Q., Zhang X., Dong X., Liu G., Wang D.: Lowmolecular weight aliphatic amides as nucleating agents for poly(L-lactic acid): Conformation variation induced crystallization enhancement. Polymer, 53, 2306-2314 (2012).

https://doi.org/10.1016/j.polymer.2012.03.034
[23] Shakoor A., Thomas N. L.: Talc as a nucleating agent and reinforcing filler in poly(lactic acid) composites. Polymer Engineering and Science, 54, 64-70 (2014). https://doi.org/10.1002/pen.23543

[24] Odent J., Raquez J-M., Leclère P., Lauro F., Dubois P.: Crystallization-induced toughness of rubber-modified polylactide: Combined effects of biodegradable impact modifier and effective nucleating agent. Polymer Advanced Technologies, 26, 814-822 (2015).

https://doi.org/10.1002/pat.3513

[25] Anakabe J., Zaldua Huici A. M., Eceiza A., Arbelaiz A., Avérous L.: Combined effect of nucleating agent and plasticizer on the crystallization behaviour of polylactide. Polymer Bulletin, 74, 4857-4886 (2017).

https://doi.org/10.1007/s00289-017-1989-z

[26] Jain S., Reddy M. M., Mohanty A. K., Misra M., Ghosh A. K.: A new biodegradable flexible composite sheet from poly(lactic acid)/poly( $\varepsilon$-caprolactone) blends and micro-talc. Macromolecular Materials and Engineering, 295, 750-762 (2010).

https://doi.org/10.1002/mame.201000063

[27] Rizzuto M., Marinetti L., Caretti D., Mugica A., Zubitur M., Müller A. J.: Can poly( $\varepsilon$-caprolactone) crystals nucleate glassy polylactide? CrystEngComm, 19, 31783191 (2017).

https://doi.org/10.1039/C7CE00578D

[28] Phromma W., Magaraphan R.: Fabrication of admicelled natural rubber by polycaprolactone for toughening poly(lactic acid). Journal of Polymers and the Environment, 26, 2268-2280 (2018).

https://doi.org/10.1007/s10924-017-1121-3

[29] Khitas N., Aouachria K., Benaniba M. T.: Blending and plasticising effects on the behaviour of poly(lactic acid)/poly( $\varepsilon$-caprolactone). Polymers and Polymer Composites, 26, 337-345 (2018). https://doi.org/10.1177/0967391118795970

[30] Sundar N., Keerthana P., Kumar S. A., Kumar G. A., Ghosh S.: Dual purpose, bio-based polylactic acid (PLA)-polycaprolactone (PCL) blends for coated abrasive and packaging industrial coating applications. Journal of Polymer Research, 27, 386 (2020). https://doi.org/10.1007/s10965-020-02320-0

[31] van de Voorde K. M., Pokorski J. K., Korley LaShanda T. J.: Exploring morphological effects on the mechanics of blended poly(lactic acid)/poly( $\varepsilon$-caprolactone) extruded fibers fabricated using multilayer coextrusion. Macromolecules, 53, 5047-5055 (2020).

https://doi.org/10.1021/acs.macromol.0c00289

[32] Oshani B. N., Davachi S. M., Hejazi I., Seyfi J., Khonakdar H. A., Abbaspourrad A.: Enhanced compatibility of starch with poly(lactic acide) and poly( $\varepsilon$-caprolactone) by incorporation of POSS nanoparticles: Study on thermal properties. International Journal of Biological Macromolecules, 141, 578-584 (2019). https://doi.org/10.1016/j.ijbiomac.2019.09.026 
[33] Wang G., Qi F., Yang W., Yang Y., He C., Peng S., Shuai C.: Crystallinity and reinforcement in poly-L-lactic acid scaffold induced by carbon nanotubes. Hindawi Advances in Polymer Technology, 2019, 8625325 (2019). https://doi.org/10.1155/2019/8625325

[34] Moeinifar E., Otadi M., Seyfi J., Khonakdar H. A.: Study on the effects of polyhedral oligomeric silsesquioxane on compatibility, crystallization behavior and thermal stability of polylactic acid/polycaprolactone blends. Polymer Bulletin, 77, 585-598 (2020). https://doi.org/10.1007/s00289-019-02766-3

[35] Chomachayi M. D., Jalali-arani A., Beltrán F. R., Ulagares de la Orden M., Urreaga J. M.: Biodegradable nanocomposites developed from PLA/PCL blends and silk fibroin nanoparticles: Study on the microstructure, thermal behavior, crystallinity and performance. Journal of Polymers and the Environment, 28, 1252-1264 (2020). https://doi.org/10.1007/s10924-020-01684-0

[36] Pantani R., Sorrention A.: Influence of crystallinity on the biodegradation rate of injection-moulded poly(lactic acid) samples in controlled composting conditions. Polymer Degradation and Stability, 98, 1089-1096 (2013). https://doi.org/10.1016/j.polymdegradstab.2013.01.005

[37] Tokiwa Y., Calabia B. P.: Biodegradability and biodegradation of poly(lactide). Applied Microbiology and Biotechnology 72, 244-251 (2006).

https://doi.org/10.1007/s00253-006-0488-1

[38] Šlouf M., Kolařík J., Kotek J.: Rubber-toughened polypropylene/acrylonitrile-co-butadiene-co-styrene blends: Morphology and mechanical properties. Polymer Engineering and Science, 47, 582-592 (2007). https://doi.org/10.1002/pen.20727

[39] Slouf M., Ostafinska A., Nevoralova M., Fortelny I.: Morphological analysis of polymer systems with broad particle size distribution. Polymer Testing, 42, 8-16 (2015). https://doi.org/10.1016/j.polymertesting.2014.12.012

[40] Turner J. F., Riga A., O’Connor A., Zhang J., Collis J.: Characterization of drawn and undrawn poly-L-lactide films by differential scanning calorimetry. Journal of Thermal Analysis and Calorimetry, 75, 257-268 (2004). https://doi.org/10.1023/B:JTAN.0000017347.08469.b1

[41] Oliver W. C., Pharr G. M.: An improved technique for determining hardness and elastic modulus using load and displacement sensing indentation experiments. Journal of Materials Research, 7, 1564-1583 (1992). https://doi.org/10.1557/JMR.1992.1564

[42] Slouf M., Pavlova E., Krejcikova S., Ostafinska A., Zhigunov A., Krzyzanek V., Sowinski P., Piorkowska E.: Relations between morphology and micromechanical properties of alpha, beta and gamma phases of iPP. Polymer Testing, 67, 522-532 (2018).

https://doi.org/10.1016/j.polymertesting.2018.03.039
[43] Slouf M., Arevalo S., Vlkova H., Gajdosova V., Kralik V., Pruitt L.: Comparison of macro-, micro- and nanomechanical properties of clinically-relevant UHMWPE formulations. Journal of the Mechanical Behavior of Biomedical Materials, 120, 104205 (2021).

https://doi.org/10.1016/j.jmbbm.2020.104205

[44] Hardiman M., Vaughan T. J., McCarthy C. T.: The effects of pile-up, viscoelasticity and hydrostatic stress on polymer matrix nanoindentation. Polymer Testing, 52, 157-166 (2016).

https://doi.org/10.1016/j.polymertesting.2016.04.003

[45] Tabor D.: The hardness of metals. Oxford University Press, New York (1951).

[46] Struik L. C. E.: Some problems in the non-linear viscoelasticity of amorphous glassy polymers. Journal of Non-Crystalline Solids, 131-133, 395-407 (1991). https://doi.org/10.1016/0022-3093(91)90333-2

[47] Balta-Calleja F. J., Fakirov S.: Microhardness of polymers. Cambridge University Press, Cambridge (2000).

[48] Flores A., Ania F., Balta-Calleja F. J.: From the glassy state to ordered polymer structures: A microhardness study. Polymer, 50, 729-746 (2009).

https://doi.org/10.1016/j.polymer.2008.11.037

[49] Ostafinska A., Vackova T., Slouf M.: Strong synergistic improvement of mechanical properties in HDPE/COC blends with fibrillar morphology. Polymer Engineering and Science, 58, 1955-1964 (2018).

https://doi.org/10.1002/pen.24805

[50] Slouf M., Strachota B., Strachota A., Gajdosova V., Bertschova V., Nohava J.: Macro-, micro- and nanomechanical characterization of crosslinked polymers with very broad range of mechanical properties. Polymers, 12, 2951 (2020).

https://doi.org/10.3390/polym12122951

[51] Vacková T., Slouf M., Nevoralová M., Kaprálková L.: HDPE/COC blends with fibrous morphology and their properties. European Polymer Journal, 48, 2031-2039 (2012).

https://doi.org/10.1016/j.eurpolymj.2012.09.005

[52] Baltá-Calleja F. J., Kilian H-G.: A novel concept in describing elastic and plastic properties of semicrystalline polymers: Polyethylene. Colloid and Polymer Science, 263, 697-707 (1985).

https://doi.org/10.1007/BF01422850

[53] Love C. T., Xian G., Karbhari V. M.: Thermal, mechanical, and adhesive properties of HDPE/reactive ethylene terpolymer blends. Journal of Applied Polymer Science, 104, 331-338 (2007).

https://doi.org/10.1002/app.24050

[54] Zipper M. D., Simon G. P., Cherry P., Hill A. J.: The effect of crystallinity on chain mobility and free volume in the amorphous regions of a miscible polycarbonate/ polyester blend. Journal of Polymer Science Part B: Polymer Physics, 32, 1237-1247 (1994). https://doi.org/10.1002/polb.1994.090320711 